\title{
Less invasive treatments for pure aortic insufficiency: Are we there yet?
}

\author{
Jessica Forcillo ${ }^{1}$
}

${ }^{1}$ Centre Hospitalier de l'Université de Montréal

January 10, 2022

\begin{abstract}
The gold standard for the treatment of pure aortic insufficiency (PAI) is surgical valve repair or replacement.1 With the newest transcatheter heart valve technologies and the accumulating years of experience of heart teams with the current transcatheter aortic valve replacement (TAVR) prostheses, implanters have push the envelope with off-label use of those valves designed and approved for aortic stenosis, in patients with pure aortic insufficiency especially those at higher risks or for compassionate use.3 However, new prostheses are currently under investigation in clinical use and evidences are provided on the safety and efficacy of those latter. It will be discussed in this commentary, the actual clinical evidences and the use of transcatheter heart valves, in and off label, for the treatment of pure aortic insufficiency.
\end{abstract}

\section{Hosted file}

Journal of Cardiac Surgery.docx available at https://authorea.com/users/351864/articles/ 552292-less-invasive-treatments-for-pure-aortic-insufficiency-are-we-there-yet 